1. Smith, G.C. 1998. The pharmacology of the ductus arteriosus. Pharmacol. Rev. 50:35-58.

2. Gittenberger-de Groot, A.C. 1977. Morphology of the normal human ductus arteriosus. In The ductus arteriosus, report of the 75th Ross Conference on Pediatric Research. M.A. Heymann and A.M. Rudolph, editors. Ross Laboratories. Columbus, Ohio, USA. 3-9.

3. Hoffman, J.I., and Kaplan, S. 2002. The incidence of congenital heart disease. J. Am. Coll. Cardiol. 39:1890-1900.

4. Heymann, M.A., Rudolph, A.M., and Silverman, N.H. 1976. Closure of the ductus arteriosus in premature infants by inhibition of prostaglandin synthesis. N. Engl.J. Med. 295:530-533.

5. Friedman, W.F., Hirschklau, M.J., Printz, M.P., Pitlick, P.T., and Kirkpatrick, S.E. 1976. Pharmacologic closure of patent ductus arteriosus in the premature infant. N. Engl. J. Med. 295:526-529.
6. Nguyen, M., et al. 1997. The prostaglandin receptor EP4 triggers remodelling of the cardiovascular system at birth. Nature. 390:78-81.

7. Loftin, C.D., et al. 2001. Failure of ductus arteriosus closure and remodeling in neonatal mice deficient in cyclooxygenase-1 and cyclooxygenase-2. Proc. Natl. Acad. Sci. U. S. A. 98:1059-1064.

8. Yokoyama, U., et al. 2006. Chronic activation of the prostaglandin receptor EP4 promotes hyaluronanmediated neointimal formation in the ductus arteriosus. J. Clin. Invest. 116:3026-3034. doi:10.1172/ JCI28639.

9. Morano, I., et al. 2000. Smooth-muscle contrac tion without smooth-muscle myosin. Nat. Cell Biol. 2:371-375.

10. Reese, J., Anderson, J.D., Brown, N., Roman, C., and Clyman, R.I. 2006. Inhibition of cyclooxygenase isoforms in late- but not mid-gestation decreases contractility of the ductus arteriosus and prevents postnatal closure in mice. Am. J. Physiol. Regul. Integr. Comp. Physiol. doi:10.1152/ajpregu.00259.2006.

11. Norton, M.E., Merrill, J., Cooper, B.A., Kuller, J.A., and Clyman, R.I. 1993. Neonatal complications after the administration of indomethacin for preterm labor. N. Engl. J. Med. 329:1602-1607.

12. Hammerman, C., et al. 1998. Indomethacin tocolysis increases postnatal patent ductus arteriosus severity. Pediatrics. 102:E56.

13. Tada, T., and Kishimoto, H. 1990. Ultrastructural and histological studies on closure of the mouse ductus arteriosus. Acta Anat. (Basel). 139:326-334.

14. Gentile, R., et al. 1981. Pulsed Doppler echocardiographic determination of time of ductal closure in normal newborn infants. J. Pediatr. 98:443-448.

15. Bergwerff, M., DeRuiter, M.C., and Gittenbergerde Groot, A.C. 1999. Comparative anatomy and ontogeny of the ductus arteriosus, a vascular outsider. Anat. Embryol. (Berl.). 200:559-571.

\title{
Role for IKK2 in muscle: waste not, want not
}

\author{
Michael Karin \\ Laboratory of Gene Regulation and Signal Transduction, Department of Pharmacology, School of Medicine, \\ University of California San Diego, La Jolla, California, USA.
}

\begin{abstract}
Activation of transcription factor NF- $\kappa B$, the major regulator of the inflammatory response, depends on the inhibitor of NF- $K B$ kinase (IKK) complex, which is composed of 2 catalytic subunits, IKK1 and IKK2 (also known as IKK $\alpha$ and IKK $\beta$ ), and a regulatory subunit, IKK $\gamma$ (also known as NEMO). In this issue of the JCI, Mourkioti et al. show that muscle-specific disruption in mice of the gene encoding IKK2 prevents NF- $\kappa B$ activation in response to denervation or toxin-induced injury (see the related article beginning on page 2945). Importantly, this genetic manipulation prevents muscle wasting, thereby providing strong evidence in support of a major pathogenic role for inflammation in a variety of muscular dystrophies characterized by progressive muscle fiber degeneration.
\end{abstract}

Transcription factor NF- $\mathrm{KB}$ is one of the major activators of the inflammatory response (1). In most cells, the majority of the NF- $\kappa \mathrm{B}$ pool resides in the cytoplasm but undergoes rapid nuclear translocation upon activation of innate immune receptors or exposure to proinflammatory cytokines, such as TNF- $\alpha$ or IL-1. Nuclear translocation of NF- $\kappa \mathrm{B}$ or its activation depends on degradation of specific inhibitory proteins called inhibitors of NF- $\mathrm{KB}$

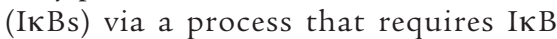
phosphorylation and polyubiquitination (2). Phosphorylation of IкBs is mediated by a specialized protein kinase complex, the IKB kinase (IKK) complex, which is

Nonstandard abbreviations used: I $\mathrm{K} B$, inhibitor of NF-кB; IKK, IкB kinase; MuRF1, muscle ring finger protein 1.

Conflict of interest: The author has declared that no conflict of interest exists.

Citation for this article: J. Clin. Invest. 116:2866-2868 (2006). doi:10.1172/JCI30268. composed of 2 catalytic subunits, IKK1 (also known as IKK $\alpha$ ) and IKK2 (also known as IKK $\beta$ ), and a regulatory subunit called NEMO or IKK $\gamma$ (3). Gene disruption experiments have established that in most cell types, in response to most

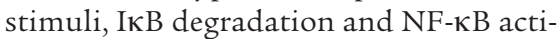
vation are mainly dependent on IKK2 (4). Hence, targeted disruption of the IKK2 gene has been used to demonstrate its involvement in a variety of inflammatory disorders, such as multiorgan dysfunction (5), colitis-associated cancer (6), and even obesity-induced insulin resistance (7). Now, in this issue of the JCI, Mourkioti et al. (8) report on the addition of muscle degeneration and atrophy to the list of pathologies that are remarkably ameliorated upon targeted deletion of IKK2. This suggests that muscle degenerative diseases may have a common inflammatory component and thus may respond to antiinflammatory therapy.

\section{A role for inflammation} in muscular dystrophies?

Muscle degeneration and atrophy is a rather common pathology associated with a variety of diseases, including those that specifically target the muscle, for instance muscular dystrophies (9), or those that target other organs, such as cancer and immune disorders $(10,11)$. Even old age and immobilization can result in muscle wasting. Yet apart from cachexia, in which TNF- $\alpha$ plays an important role, and specific muscle inflammation/myositis, muscular dystrophies in particular and muscle atrophy in general have not been universally thought of as inflammatory diseases. Yet the new work of Mourkioti et al. (8) as well as previous work by Shoelson's group that demonstrated severe muscle wasting following the constitutive activation of NF-KB in muscle cells (12) clearly demonstrate the involvement of the $\mathrm{IKK} / \mathrm{NF}-\mathrm{\kappa B}$ signaling system in different types of muscle degeneration. These data therefore strongly suggest that muscular dystrophies and atrophies should also be considered inflammatory diseases and raise the prospects of novel therapies that target IKK2 or other steps in the NF-кB activation pathway.

Mourkioti et al. (8) used a mouse strain homozygous for a conditional Ikk2 allele (a so-called floxed allele) that can be deleted upon expression of Cre-recombinase to specifically inactivate IKK2 in 


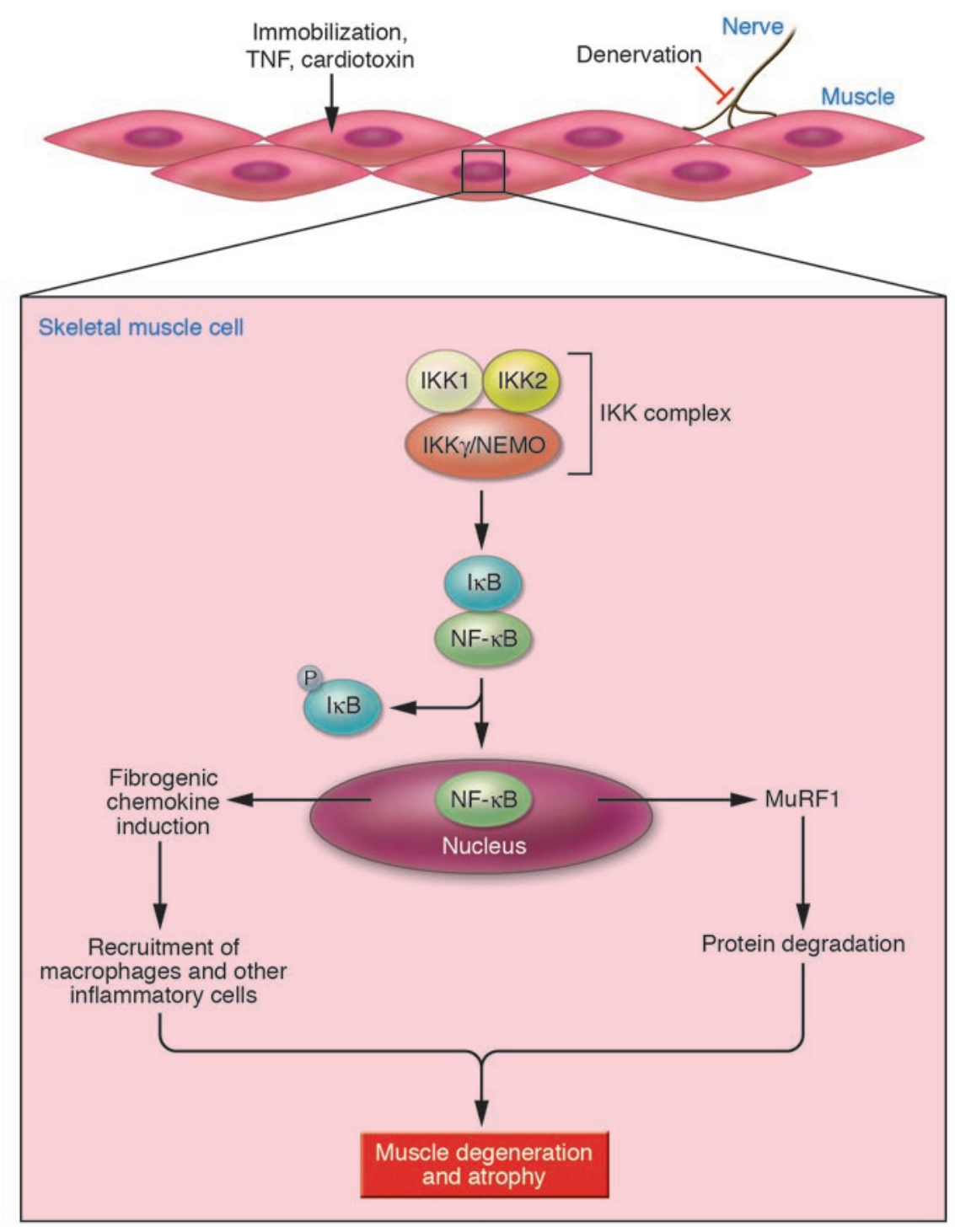

skeletal muscle. As a result, the mutant mice, named IKK2 $2^{\text {mko }}$ mice, expressed an IKK2-deficient IKK complex (containing only IKK1 and IKK $\gamma$ ) and were unable to mount NF- $\kappa \mathrm{B}$ activation in muscle. NF- $\kappa \mathrm{B}$ activity was elicited in this study in response to denervation of the sciatic nerve, which causes degeneration of the leg muscles, or by direct induction of muscle degeneration by injection of cardiotoxin. Importantly, deletion of IKK2 increased muscle mass and strength in untreated mice and led to maintenance of close to normal muscle mass and function in mice subjected to denervation or cardiotoxin injection (8). The same group previously found that overexpression of IGF-1 also protects against muscle degeneration in these models and causes increased muscle mass in untreated ani- mals (13). In their new article (8), they show that IGF-1 overexpression acts additively with IKK2 deletion, resulting in very impressive maintenance of muscle mass and no muscle degeneration after denervation. Interestingly, inhibition of NF- $\kappa \mathrm{B}$ activation by deletion of IKK2 seemed to mediate its protective effects in part by preventing induction of the ubiquitin ligase muscle ring finger protein 1 (MuRF1), previously shown to be a critical regulator of muscle degeneration (14) and to be induced upon NF-кB activation in muscle (12). In contrast, IGF-1 exerted its muscle-protective effect by reducing expression of another ubiquitin ligase involved in muscle atrophy - atrogin-1 (also known as muscle atrophy F-box protein $[\mathrm{MAFbx}])(15,16)$. In addition, deletion of IKK2 accelerated muscle

\section{Figure 1}

Denervation, immobilization, toxins, and cachexia (mediated by TNF- $\alpha$ ) induce muscle degeneration and atrophy through the activation of IKK and NF-KB in muscle cells. Once activated, NF-KB leads to upregulation of MuRF1, a ubiquitin ligase involved in degradation of muscle proteins. NF- $\mathrm{KB}$ activation also leads to induction of chemokines that recruit inflammatory cells, such as macrophages, that can cause further muscle damage. $\mathrm{P}$, phospho-. regeneration either by stimulating the proliferation of satellite cells or enhancing the recruitment of newly formed myoblasts into damaged muscle fibers (8). Prevention of NF- $\kappa \mathrm{B}$ activation also inhibited injury-induced fibrosis. This effect is most likely due to diminished expression of fibrogenic cytokines, some of which may be regulated transcription-

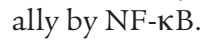

\section{Mechanistic and therapeutic implications}

In addition to controlling the expression of proinflammatory cytokines and enzymes involved in the production of secondary inflammatory mediators, NF- $\mathrm{B}$ activates the expression of critical antiapoptotic genes (17). Thus, deletion of IKK2 or inhibition of NF-KB activation 
quite frequently results in increased apoptosis (and even necrosis) in cells exposed to TNF- $\alpha(18-20)$. Thus, the findings of Mourkioti et al. (8), as well as those of Cai et al. (12), showing that inhibition of NF- $\kappa \mathrm{B}$ activation prevents muscle degeneration and myofiber death (Figure 1) are truly remarkable and raise a few interesting questions. First, which target genes mediate the induction of muscle degeneration in response to NF- $\mathrm{KB}$ activation? Is $M u R F 1$ the only NF- $\kappa \mathrm{B}$ target gene involved in this response, or is there a role for other $\mathrm{NF}-\kappa \mathrm{B}$ targets? For instance, NF- $\mathrm{B}$ is known to regulate the expression of many chemokines (21), which may recruit inflammatory cells to sites of injury and thereby cause more tissue damage. Another puzzle is why the inhibition of NF- $\mathrm{KB}$ in muscle cells does not result in TNF- $\alpha$ induced apoptosis as commonly observed in other NF-KB-deficient cell types.

While we need to wait for further research to answer these questions, the findings of Mourkioti et al. (8) and Cai et al. (12) strongly suggest that it is necessary to evaluate the ability of NF- $\kappa$ B inhibition to prevent muscle degeneration in various models of muscular dystrophy and atrophy, first in mice and then in humans. Several small molecule inhibitors of NF- $\mathrm{\kappa B}$ activation, either of natural origin or the products of synthetic chemistry, have been described (22). While many of them are not very specific or potent, IKK2 inhibitors (23) or effective NF- $\kappa \mathrm{B}$ activation inhibitors with an unknown mechanism of action (24) have recently become available. Given the prevalence of muscle degenerative diseases and their toll on life quality as well as their major economic impact, such trials are not only justified but also badly needed.

Address correspondence to: Michael Karin, Laboratory of Gene Regulation and Signal Transduction, Department of Pharmacology, School of Medicine, University of California, San Diego, 9500 Gilman Drive, La Jolla, California 92093-0636, USA. Phone: (858) 534-1361; Fax: (858) 534-8158; E-mail: karinoffice@ucsd.edu.

1. Barnes, P.J., and Karin, M. 1997. Nuclear factor-kap$\mathrm{paB}$ : a pivotal transcription factor in chronic inflammatory diseases. N. Engl. J. Med. 336:1066-1071.

2. Ghosh, S., and Karin, M. 2002. Missing pieces in the NF-kB puzzle. Cell. 109(Suppl.):S81-S96.

3. Rothwarf, D.M., and Karin, M. 1999. The NF-kB activation pathway: a paradigm in information transfer from membrane to nucleus. Sci. STKE. 1999:RE1.

4. Li, Q., and Verma, I.M. 2002. NF-kB regulation in the immune system. Nat. Rev. Immunol. 2:725-734.

5. Chen, L.W., et al. 2003. The two faces of IKK and NF-kB inhibition: prevention of systemic inflammation but increased local injury following intestinal ischemia-reperfusion. Nat. Med. 9:575-581.

6. Greten, F.R., et al. 2004. IKKb links inflammation and tumorigenesis in a mouse model of colitisassociated cancer. Cell. 118:285-296.

7. Arkan, M.C., et al. 2005. IKKb links inflammation to obesity-induced insulin resistance. Nat. Med. 11:191-198.

8. Mourkioti, F., et al. 2006. Targeted ablation of IKK2 improves skeletal muscle strength, maintains mass, and promotes regeneration. J. Clin. Invest. 116:2945-2954. doi:10.1172/JCI28721.

9. Nowak, K.J., and Davies, K.E. 2004. Duchenne muscular dystrophy and dystrophin: pathogenesis and opportunities for treatment. EMBO Rep. 5:872-876.
10. Tisdale, M.J. 2002. Cachexia in cancer patients. Nat. Rev. Cancer. 2:862-871.

11. Dalakas, M.C. 2004. Inflammatory disorders of muscle: progress in polymyositis, dermatomyositis and inclusion body myositis. Curr. Opin. Neurol. 17:561-567.

12. Cai, D., et al. 2004. IKKb/NF-kB activation causes severe muscle wasting in mice. Cell. 119:285-298.

13. Musaro, A., et al. 2001. Localized Igf-1 transgene expression sustains hypertrophy and regeneration in senescent skeletal muscle. Nat. Genet. 27:195-200.

14. Bodine, S.C., et al. 2001. Identification of ubiquitin ligases required for skeletal muscle atrophy. Science. 294:1704-1708.

15. Stitt, T.N., et al. 2004. The IGF-1/PI3K/Akt pathway prevents expression of muscle atrophy-induced ubiquitin ligases by inhibiting FOXO transcription factors. Mol. Cell. 14:395-403.

16. Sandri, M., et al. 2004. Foxo transcription factors induce the atrophy-related ubiquitin ligase atrogin-1 and cause skeletal muscle atrophy. Cell. 117:399-412.

17. Karin, M., and Lin, A. 2002. NF-kB at the crossroads of life and death. Nat. Immunol. 3:221-227.

18. Chang, L., et al. 2006. The E3 ubiquitin ligase itch couples JNK activation to TNFa-induced cell death by inducing c-FLIP(L) turnover. Cell. 124:601-613.

19. Van Antwerp, D.J., Martin, S.J., Kafri, T., Green, D.R., and Verma, I.M. 1996. Suppression of TNFainduced apoptosis by NF-kB. Science. 274:787-789.

20. Kamata, H., et al. 2005. Reactive oxygen species promote TNFa-induced death and sustained JNK activation by inhibiting MAP kinase phosphatases. Cell. 120:649-661.

21. Bonizzi, G., and Karin, M. 2004. The two NF-kB activation pathways and their role in innate and adaptive immunity. Trends Immunol. 25:280-288.

22. Karin, M., Yamamoto, Y, and Wang, Q.M. 2004 The IKK NF-kB system: a treasure trove for drug development. Nat. Rev. Drug Discov. 3:17-26.

23. Burke, J.R., et al. 2003. BMS-345541 is a highly selective inhibitor of IkB kinase that binds at an allosteric site of the enzyme and blocks NF-kB-dependent transcription in mice. J. Biol. Chem. 278:1450-1456.

24. Sharma, V., Lansdell, T.A., Peddibhotla, S., and Tepe, J.J. 2004. Sensitization of tumor cells toward chemotherapy: enhancing the efficacy of camptothecin with imidazolines. Chem. Biol. 11:1689-1699. 